\title{
General editors' preface
}

Television is part of our everyday experience, and is one of the most significant aspects of our cultural lives today. Yet its practitioners and its artistic and cultural achievements remain relatively unacknowledged. The books in this series aim to remedy this by addressing the work of major television writers and creators. Each volume provides an authoritative and accessible guide to a particular practitioner's body of work, and assesses his or her contribution to television over the years. Many of the volumes draw on original sources, such as specially conducted interviews and archive material, and all of them list relevant bibliographic sources and further reading and viewing. The author of each book makes a case for the importance of the work considered therein, and the series includes books on neglected or overlooked practitioners alongside well-known ones.

In comparison with some related disciplines, Television Studies scholarship is still relatively young, and the series aims to contribute to establishing the subject as a vigorous and evolving field. This series provides resources for critical thinking about television. While maintaining a clear focus on the writers, on the creators and on the programmes themselves, the books in this series also take account of key critical concepts and theories in Television Studies. Each book is written from a particular critical or theoretical perspective, with reference to pertinent issues, and the approaches included in the series are varied and sometimes dissenting. Each author explicitly outlines the reasons for his or her particular focus, methodology or perspective. Readers are invited to think critically about the subject matter and approach covered in each book.

Although the series is addressed primarily to students and scholars of television, the books will also appeal to the many people who are interested in how television programmes have been commissioned, made and enjoyed. Since television has been so much a part of personal 


\section{xii General editors' preface}

and public life in the twentieth and twenty-first centuries, we hope that the series will engage with, and sometimes challenge, a broad and diverse readership.

Jonathan Bignell Steven Peacock 